\title{
Use of Family Planning Services in the Transition To a Static Clinic System in Bangladesh: 1998-2002
}

\begin{abstract}
CONTEXT: In rural Bangladesh, family planning services—previously provided through household visits and satellite clinics - were transferred to static community clinics under the government's sectoral program for 1998-2003, but the next sectoral program reversed the change without a formal evaluation. It is important to assess changes in utilization and coverage to inform further development of the service delivery system.
\end{abstract}

METHODS: Longitudinal data on use offamily planning services and contraceptive methods were collected quarterly in 1998-2002 from married women in about 11,000 households in two rural surveillance areas-Abhoynagar and Mirsarai. Cross-sectional surveys were conducted among women and service providers in 2003 to gather detailed information about the transition to static clinics and women's response to the changes. Quarterly time series graphs of selected indicators were plotted for areas served by community clinics.

RESULTS: In a time of considerable change in service delivery and sources of contraceptive supply, contraceptive prevalence remained constant in Abhoynagar and increased in Mirsarai. Community clinics quickly became the source of supplies for one-third of contraceptive users in Abhoynagar and one-fifth in Mirsarai. In wards where community clinics became operational (mostly in 2001-2002), three-quarters of women had used one at some time.

CONCLUSIONS: Despite cultural constraints on mobility, women do not appear to have become dependent on home delivery of contraceptives.

International Family Planning Perspectives, 2005, 31(3):115-123

Household delivery of family planning services was introduced in Bangladesh in 1978 and probably contributed to the rapid decline in the total fertility rate from 6.3 in 1971-1975 to 3.4 in 1991-1993. ${ }^{1}$ Under this system, 23,500 female fieldworkers (officially known as family welfare assistants) were introduced by the government and 12,000 by nongovernmental organizations (NGOs) to counsel, motivate and distribute contraceptive supplies to rural women in their homes. The government fieldworkers supplied 85\% of all contraceptive pills, condoms and injectables in some areas. $^{2}$

Several considerations led the government to introduce a different system of service delivery under its Health and Population Sector Programme for 1998-2003 (HPSP). With the number of married women of reproductive age (referred to from here on simply as women) rising, domiciliary services would require increasing resources. ${ }^{3}$ Financial sustainability was a major concern for international donors, and continuing with household delivery would raise program costs. ${ }^{4}$ Moreover, coverage was poor: The majority of Bangladeshi women participating in Demographic and Health Surveys (DHS) in the 1990s reported that they had not been visited by a fieldworker in the past six months. ${ }^{5}$ There were also concerns that the program mainly promoted temporary methods, and that the quality of services was being negatively affected by inadequate training, supervision and management.
The HPSP identified an extended range of health and family planning services, the Essential Services Package (ESP). These services would be provided through community clinics built to serve catchment populations of about $6,000 .{ }^{6}$ Fieldworkers engaged in household delivery would be retrained; one female and one male fieldworker (officially known as a health assistant) would be assigned to each community clinic, making selective household visits one day a week. At first, paramedics would continue to provide reproductive and child health services once a month at various satellite clinic locations, usually private houses. As community clinics became operational, they would take over these services, and routine domiciliary services would be phased out.

These supply-side changes would necessitate a major change in women's service-seeking behavior. ${ }^{7}$ Some suggested that phasing out home delivery might reduce contraceptive use, especially in a culture that has traditionally restricted women's movements. ${ }^{8}$ An operations research study conducted in 1996-1998 suggested that women would obtain contraceptives from a satellite clinic serving 40-50 households if home delivery were phased out, but this was service provision at a more local level. Static clinics were implemented in some NGO-served areas, and data from three such areas indicated that women did not face insurmountable barriers to obtaining family planning services outside the home. ${ }^{9}$
ByAlex Mercer, Ali Ashraf, Nafisa Lira Huq, Fariha Haseen, AH Nowsher Uddin and Masud Reza

Alec Mercer is health demographer; Ali Ashraf is senior operations researcher, and Nafisa Lira Huq, Fariha Haseen, AH Nowsher Uddin and Masud Reza are members of the research team-all at Health Systems and Infectious Diseases Division, International Centre for Diarrhoeal Disease Research, Bangladesh, Centre for Health and Population Research, Dhaka. 
The process of building more than 13,000 community clinics and making them operational was much delayed and remained incomplete at the end of the government's term. By December 2002, 9,413 community clinics had been constructed, of which 6,706 were "functioning." ${ }^{10}$ However, no upazilas (subdistricts) had fully implemented the static clinic system. Even within unions (upazilla subdivisions of about 25,000 people), not all administrative wards (three per union) had a community clinic functioning in some capacity. The government elected in 2002 formally abandoned the community clinic system in 2003, and the Ministry of Health and Family Welfare (MOHFW) reintroduced domiciliary services and satellite clinics under the sectoral program for 2004-2007. ${ }^{11}$ However, the decision was not based on any formal evaluation of the static clinic system.

In 2001, the International Centre for Diarrhoeal Disease Research, Bangladesh (ICDDR,B) Centre for Health and Population Research conducted a preliminary assessment of two community clinics in two of its surveillance areas. ${ }^{12}$ The center had helped the government develop the community clinic guidelines and implement changes in these areas. When the study clinics had been operating for six and 11 months, respectively, service provision was found to comply reasonably well with the guidelines. ${ }^{13}$ Use of such key ESP services as family planning had not declined, although the assessment report acknowledged that a longer follow-up in more catchment areas would be required to assess the impact of static clinic service delivery.

This article is based on a larger study of ESP service use during the transition to a static clinic system in two ICDDR,B surveillance areas. User-reported data are important in developing a responsive, user-centered service delivery system, particularly because local-level data are not available from national surveys. The 1999-2000 and 2004 DHS and the 2000 Service Delivery Survey by the Canadian Institute for Energy Training (CIET) provide national estimates of service use and satisfaction, but were not conducted in 2001-2002, when most community clinics were operating. ${ }^{14}$ We report on trends in family planning service use and coverage in the two surveillance areas between 1998 and 2002, focusing on wards in which at least one community clinic became operational.

\section{METHODS}

Our study was based on data from three types of survey: longitudinal quarterly surveys of households in the two surveillance areas between 1998 and 2002; a cross-sectional survey of women in 2003; and a survey of local managers,

*We considered a community clinic to be operational if a female family welfare assistant or a male health assistant attended on most working days and if the facility had provided at least some reproductive health services for 12 or more continuous months in 2001-2002.

tHousehold income is not routinely measured in the surveillance areas, and data on other direct measures of poverty are not up to date. However, cross-sectional data from 2003 indicate that the majority of women in both socioeconomic groups would be classified as poor according to international definitions of poverty based on household income (e.g., less than US\$1 per person per day). supervisors and community clinic service providers in 2003. Although many community clinics did not operate long enough to have a major impact on family planning service use and contraceptive prevalence, it is useful to review trends for areas in which they became operational. * Because most clinics did not become operational until 2001-2002, data from 1998-2000 can be used for comparison. Service use data are available for wards in which no clinic became operational, but given space limitations, we consider only contraceptive prevalence when comparing these wards with wards that had an operational clinic.

\section{Study Sites and Population}

ICDDR,B has conducted demographic and health service surveillance in field sites in five unions of Abhoynagar upazila since 1982 and in five unions of Mirsarai upazila since 1994. Surveillance has been conducted in two additional unions of Mirsarai since 1999. Because the government alone has provided ESP services in both surveillance areas, the data are valuable in evaluating its service delivery system.

The study population comprised all married women aged 15-49 in about 11,000 households under surveillance in the rural wards of these unions. Because the sectoral program was intended to improve access to ESP services for the poor, we identified a low socioeconomic status group that consisted of women with no schooling or a day-laborer husband. ${ }^{\dagger}$ The remaining women were classified as "others."

\section{Data Collection}

- Quarterly surveillance survey. Sampling fractions for surveillance households were one in six in Abhoynagar and one in four in Mirsarai. In the third quarter of 2002, there were 4,635 women in surveillance households in Abhoynagar and 6,511 in those in Mirsarai. Women in clinic wards constituted the main sample for longitudinal analysis (2,426 in Abhoynagar and 2,797 in Mirsarai). Data were collected in quarterly survey rounds by field research assistants who asked women about their reproductive and contraceptive status, pregnancy outcomes, use of contraceptives, method choice and source of supply; whether they had visited a government health facility or received a home visit from a fieldworker in the previous three months; and what services they had received.

- Cross-sectional survey of women. The survey was conducted in September 2003 among a random sample of women under surveillance to collect detailed information about changes in service delivery and service-seeking behavior. Interviewers used structured questionnaires to ask women about their knowledge and experience of the changes in service delivery that had occurred in their ward; awareness of services provided at the community clinic; use of the clinic for various services; whether they were satisfied with community clinics; why they felt this way; and how supply-side changes had affected their service-seeking behavior.

Using standard formulas, we calculated that a sample size of 384 women would give the required level of precision $( \pm 0.05)$ in estimates of proportions for various sub- 
groups, given an estimated proportion of .50 with 95\% confidence limits. Sampling was stratified by socioeconomic status. In clinic wards, four samples of 384 women each were randomly selected from the surveillance database from among 1,028 in Abhoynagar and 1,011 in Mirsarai: women of low socioeconomic status who had used a community clinic; women of low socioeconomic status who had never used one; others who had used one; and others who had never used one.

- Survey of managers and service providers. Senior researchers conducted semistructured interviews with local MOHFW managers: upazila health and family planning officers, medical officers-maternal and child health, and both current and previous upazila family planning officers. Respondents provided information on the process and timing of changes in service delivery, number of clinics, fieldworker training and assignment, provision of supplies, functioning of community clinics and services provided.

After a two-day training workshop, experienced interviewers used structured questionnaires to collect information from supervisors and community clinic service providers. Topics included the process of transition to community clinics, training, services provided, current operational status, organization and maintenance, supply, and the withdrawal of home visits and satellite clinics.

\section{Indicators}

Using data from the quarterly survey, we reviewed trends in selected indicators to assess the extent to which women adopted new sources of family planning supplies under the static clinic system. We considered proportions of women reporting visits to community clinics, satellite clinics and other government facilities in the past three months, and the proportion reporting home visits by fieldworkers during that time. We also looked at the proportion of women currently using contraceptives, method choice and source of supply. DHS estimates of contraceptive prevalence in various administrative divisions and in rural Bangladesh as a whole are presented for comparison.*

\section{Data Analysis}

We plotted quarterly time series graphs of selected indicators for all clinic wards combined for each surveillance area. Trends were interpreted in relation to the period when most community clinics were operational (2001-2002). Graphs for Abhoynagar were based on continuous series of comparable data for the whole study period. In Mirsarai, two unions were added to surveillance in 1999. However, we found sufficient comparability in the indicators to present trends for the whole period. (Data on contraceptive prevalence in the transition quarter have been omitted.)

We used data from local managers to cross-check classification of clinic wards based on information from supervisors and community clinic service providers. Data from the latter group were cross-checked for consistency and used to assess what service delivery system was actually in operation during the study period.
FIGURE 1. In wards of Abhoynagar and Mirsarai with an operational community clinic, percentage of married women aged 15-49 who obtained government health services from specific sources, by quarter, 1998-2002

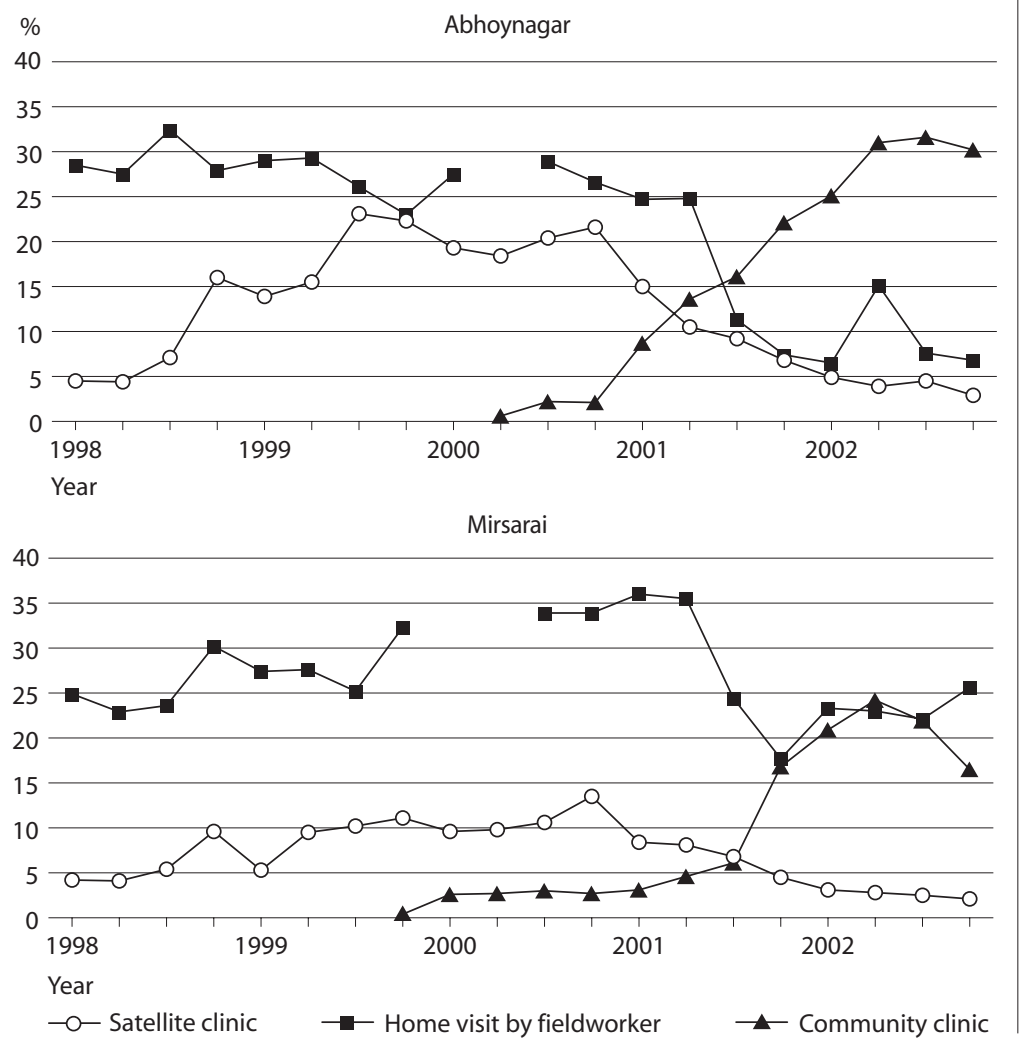

\section{RESULTS}

\section{Transition to Static Clinics}

Local managers decided where to locate community clinics for optimal access, considering population distribution and consultations with fieldworkers. Fieldworkers were assigned to clinics and received three weeks' training in family planning and other services from upazila and district managers. Some of the supplies sent from districts for upazilas were distributed to community clinics by the health and family planning officers; inadequate supplies, particularly of medicines, led to shortages in the clinics. Satellite clinics near operational community clinics were discontinued. Local managers reported that people had few problems switching to community clinics and generally accepted the system. All fieldworkers reported that operational community clinics provided family planning services, antenatal care, immunization and treatment for common health problems.

Nearly all community clinics that became operational did so in 2001; one clinic in each upazila opened in late 2000. One of the five surveillance unions in Abhoynagar never had a functioning community clinic. Of the 12 wards in the other four unions, one had no community clinic in operation; three had a union-level health and family welfare center, so no community clinic was built; and eight had at least one op-

*The DHS included married women aged 10-49 (vs. 15-49 in our study), but there were so few 10-14-year-olds that the rates are comparable. 


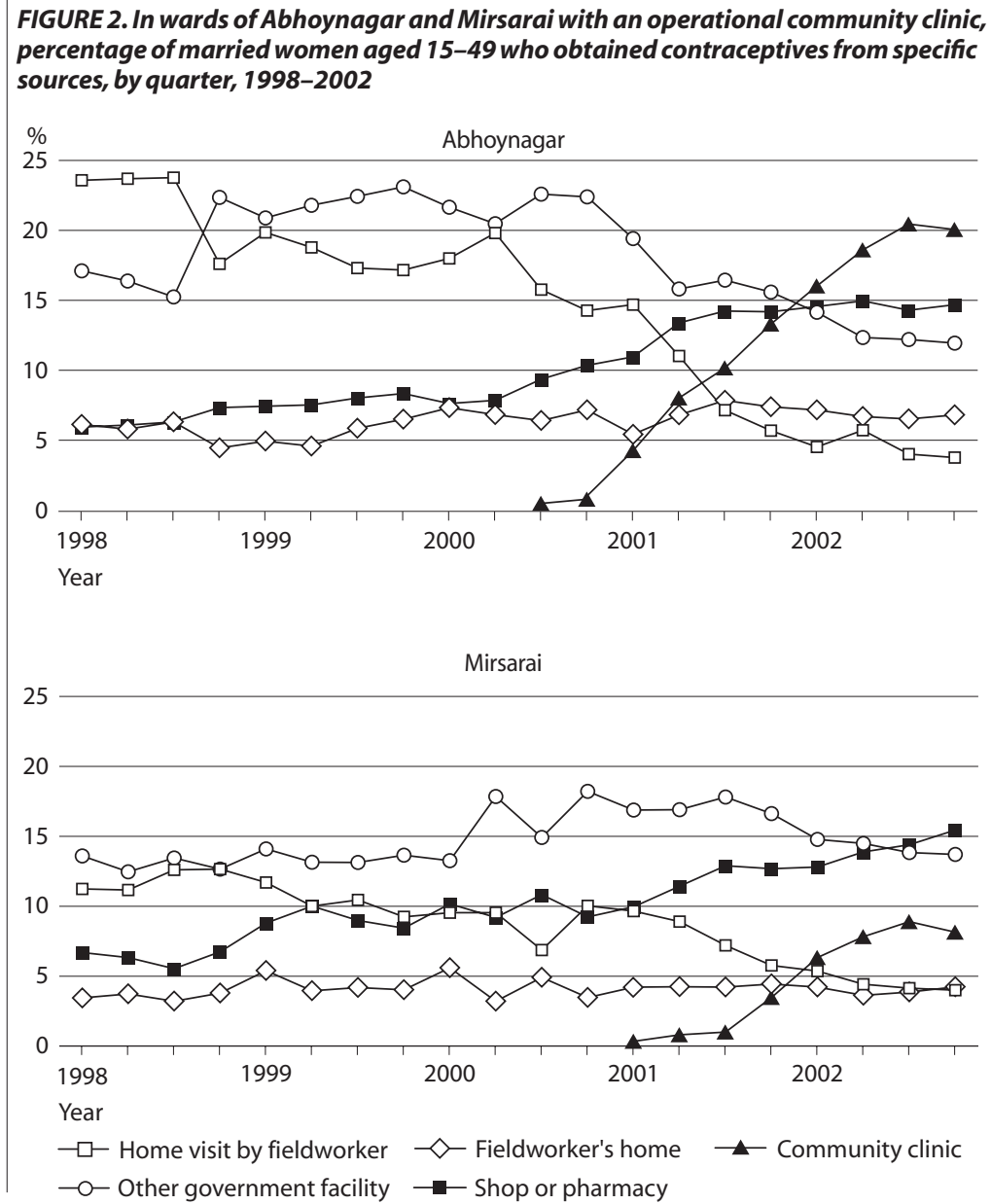

erational community clinic. In three of the seven surveillance unions in Mirsarai, none of the planned community clinics were built. Of the 12 wards in the other four unions, three had no operational community clinic; three had a health and family welfare center; and six had at least one operational community clinic. Thus Abhoynagar contained eight clinic wards and seven nonclinic wards, and Mirsarai contained six clinic wards and 15 nonclinic wards.

FIGURE 3. In wards of Abhoynagar and Mirsarai with and without an operational community clinic, percentage of married women aged 15-49 who used contraceptives, by quarter, 1998-2002

\section{$\%$}

70

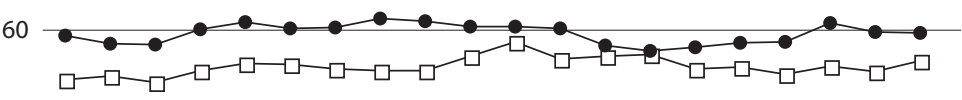

50

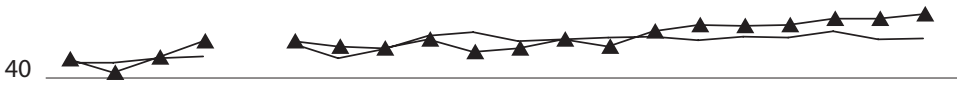

30

$\begin{array}{lcccc}1998 & 1999 & 2000 & 2001 & 2002 \\ \text { Year } & & & & \\ \longrightarrow & & & \\ & & & \end{array}$

\section{Use of Government Services}

Figure 1 (page 117) shows that in wards with operational community clinics, the strategic shift from reliance on home delivery and satellite clinics to use of static clinics was largely achieved. From 1998 to 2000, the proportion of women reporting a home visit by a female fieldworker in the previous three months generally remained between $20 \%$ and $35 \%$, except in mid-2000, when fieldworkers assisted with an annual census. In comparison, $21 \%$ of all women in rural Bangladesh had been visited by a government fieldworker for family planning services in the six months preceding the 1999-2000 DHS. ${ }^{15}$ When community clinics were functioning (2001-2002), the proportion reporting home visits in each quarter declined from about 30\% to $10 \%$ in Abhoynagar and from about 35\% to 20\% in Mirsarai. The proportion of women who had used a satellite clinic in the past three months also declined in this period, from about $20 \%$ to $5 \%$ in Abhoynagar and from about 10\% to 2\% in Mirsarai.

In Abhoynagar, the proportion of women reporting a visit to a community clinic in the past three months increased steadily in 2001 before leveling off in 2002 at 30-35\% among women of low socioeconomic status and 25-30\% among others. In Mirsarai, most community clinics became operational in the second half of 2001; the proportion of women who used these facilities in each quarter then increased, peaking at 20-30\% among women of low socioeconomic status and 15-20\% among others in mid-2002.

\section{Sources of Contraceptives}

Community clinics quickly became a major source of contraceptives in 2001 and 2002 in clinic wards of both areas and became the most common source in Abhoynagar (Figure 2). By the middle of 2002, static clinics were supplying about $20 \%$ of women (one-third of all contraceptive users) in Abhoynagar and about 9\% (one-fifth of users) in Mirsarai. In both areas, the proportion of women who obtained contraceptives from other government facilities, including satellite clinics, declined in the period when services were being transferred to community clinics.

Throughout 1998-2002, about 5\% of women obtained contraceptives at a fieldworker's house, which was consistent with the strategy of encouraging women to seek services outside the home. The proportion of women obtaining contraceptives through home delivery declined in Abhoynagar from about 20-25\% in 1998 to about 5\% in 2002 ; it declined from about $10-15 \%$ to $5 \%$ during that time in Mirsarai. The decline in 2001-2002 in part reflects the reduction in reported home visits shown in Figure 1. However, supply through home delivery also decreased in 1998-2000, before community clinics had become operational and fieldworkers had been reassigned, and before reported home visits showed substantial declines.

As visits by fieldworkers decreased, women switched to shops and pharmacies as well as to community clinics (Figure 2), although there had been a steady increase in use of the latter before community clinics became operational. 
The proportion of women reporting these sources increased in both areas from about 5\% to 10\% between 1998 and 2000 , then rose to $15 \%$ by the end of 2002 . However, in the 2003 survey, about $90 \%$ of contraceptive users who relied on shops and pharmacies reported that their husband went to buy the supplies; there was little difference between women of low socioeconomic status and other women (see Table 1, page 120).

\section{Trends in Contraceptive Prevalence}

The proportion of women using any method remained at about 60\% in clinic wards of Abhoynagar in 1998-2002, despite considerable changes in service delivery and sources of contraceptives (Figure 3). In Mirsarai, the proportion increased from about $40 \%$ to $47 \%$. Trends in clinic wards were similar to those in nonclinic wards: In nonclinic wards of Mirsarai, there was an increase in prevalence similar to that in clinic wards; in Abhoynagar, the trend in nonclinic wards was fairly flat, as it was in clinic wards, albeit at a lower level throughout the study period.

In clinic wards of both areas, the most popular methods were the pill and the injectable, and use of the pill increased between 1998 and 2002 (Figure 4). In Abhoynagar, the proportion of women relying on the pill remained at about $20 \%$ from 1998 to 2000, after which it increased to about 25\% by early 2001. There was some indication of a shift from the injectable to the pill: The proportion using the injectable was just over 20\% in 1998-2000, but dipped below 20\% in 2001. This accounts for most of the slight dip in Abhoynagar's overall contraceptive prevalence in 2001 (Figure 3). In Mirsarai, the increase in overall prevalence largely reflects an increase in pill use throughout the study period, from about $16-18 \%$ in 1998 to $22-24 \%$ in 2002.

Between 1998 and 2002, the proportion of women reporting tubal sterilization declined from about $6 \%$ to $4 \%$ in Abhoynagar and from about 5\% to 3\% in Mirsarai. Very few husbands had had a vasectomy. The proportion of women using an IUD remained at 2-3\% in clinic wards of both areas, and use of the implant increased to about $2 \%$. The proportion of women reporting traditional methods remained between $2 \%$ and $4 \%$ throughout the study period.

\section{User Response to the Static Clinic System}

According to data from the 2003 survey, relatively small proportions of women in clinic wards reported having experienced a problem when satellite clinic services were transferred to a community clinic (11\% in Abhoynagar and 2\% in Mirsarai-Table 1). The most common problem was a longer walk, although the maximum travel time was 30 minutes (data not shown).

Three-quarters of women who had a community clinic in their ward had used it at least once. In Abhoynagar, the proportion was particularly high among women aged 15-29 and among those with no schooling (83\% and 92\%, respectively). In Mirsarai, the proportion of women who had visited a community clinic was significantly higher among those reporting a monthly per capita household expendi-
FIGURE 4. In wards of Abhoynagar and Mirsarai with an operational community clinic, percentage of married women aged 15-49 who used selected methods of contraception, by quarter, 1998-2002

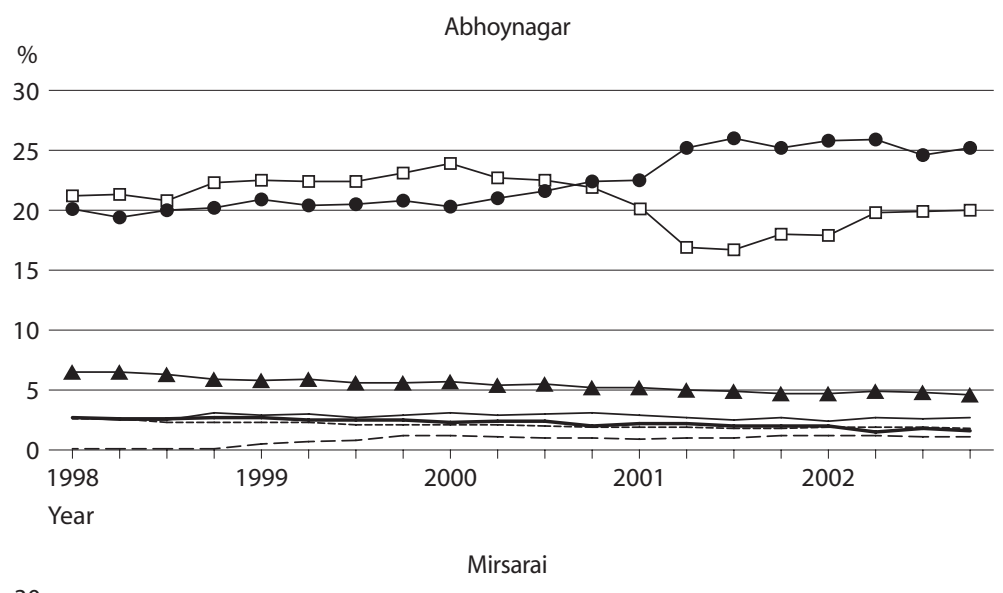

30

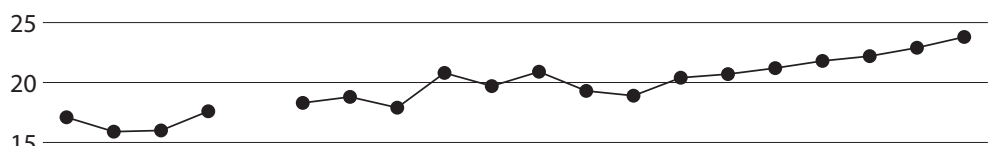
$15 \longrightarrow$
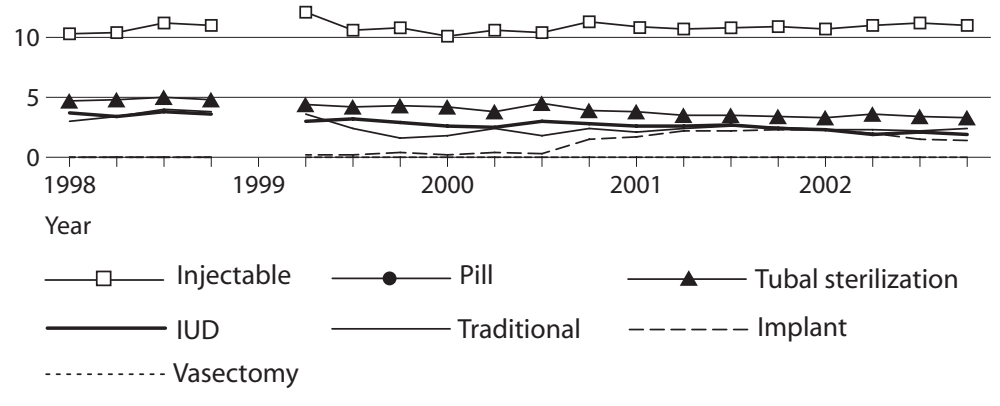

ture of less than Taka 500 (US\$8) than among those reporting Taka 1,000 or more ( $83 \%$ vs. $60 \%$; $<<0.05$ ). The differential was similar and statistically significant in Abhoynagar (79\% vs. 65\%; p<.05).

More women in Abhoynagar than in Mirsarai had attended a community clinic in the past six months (62\% vs. $32 \%$ ). Of these women, a majority reported satisfaction with the services they had received (74\% and 54\%, respectively). Among those who were satisfied, the most common reasons were that the community clinic was close by ( $42 \%$ and $44 \%$ ); services were good (38\% and $6 \%$ ); and many services were available in one place (14\% and 3\%). Among those who were dissatisfied, the most common reasons were lack of medicines (65\% and $27 \%$ ) and not all services being available (17\% and 13\%). Most women who had attended a community clinic for family planning services in the previous six months had received the service they sought (97\% in Abhoynagar and 73\% in Mirsarai). Despite changes in sources of contraceptive supplies, relatively small proportions of current users had switched methods in the last two years (21\% and $11 \%$-data not shown). Among those who had switched, the most common reason was side effects (79\% and $74 \%$ ) rather than problems with the service delivery system (7\% and 10\%). 


\begin{tabular}{|c|c|c|}
\hline Subgroup & Abhoynagar & Mirsarai \\
\hline HAD COMMUNITY CLINIC IN WARD & $(\mathrm{N}=677)$ & $(\mathrm{N}=585)$ \\
\hline Had problems when satellite clinic closed & $10.6(8.3-12.9)$ & $1.7(0.6-2.7)$ \\
\hline \multicolumn{3}{|l|}{ Ever used a community clinic } \\
\hline \multicolumn{3}{|l|}{ Age 100 - } \\
\hline $15-19$ & $82.7(78.4-87.0)$ & $71.3(65.6-77.2)$ \\
\hline $30-49$ & $70.5(65.6-75.4)$ & $67.8(63.4-73.4)$ \\
\hline \multicolumn{3}{|l|}{ Schooling } \\
\hline None & $92.2(87.6-96.8)$ & $73.6(68.2-79.0)$ \\
\hline Some & $72.2(68.3-76.1)$ & $66.3(61.0-71.6)$ \\
\hline \multicolumn{3}{|l|}{ Monthly per capita household expenditure } \\
\hline$<$ Tk500 & $79.3(73.3-85.3)$ & $82.7(72.4-93.0)$ \\
\hline$\geq \operatorname{Tk} 1,000$ & $64.7(52.0-78.6)$ & $60.0(52.7-72.3)$ \\
\hline Report home visits would still be useful & $79.1(76.0-82.2)$ & $85.3(82.5-88.1)$ \\
\hline \multicolumn{3}{|c|}{ Prefer community clinics to satellite clinic/home visits } \\
\hline Low SESt & $54.5(48.9-60.1)$ & $53.7(48.0-59.4)$ \\
\hline Other & $54.5(49.5-59.5)$ & $54.8(49.1-60.5)$ \\
\hline VISITED COMMUNITY CLINIC IN PAST 6 MOS. & $(\mathrm{N}=422)$ & $(\mathrm{N}=189)$ \\
\hline Satisfied with service provided & $74.1(69.9-78.3)$ & $54.0(46.9-61.1)$ \\
\hline \multicolumn{3}{|l|}{ Reasons for satisfaction } \\
\hline Clinic near to house & $42.2(36.7-47.7)$ & $44.4(37.3-51.5)$ \\
\hline Good service quality & $38.2(32.8-43.6)$ & $5.8(2.5-9.1)$ \\
\hline Many services in one place & $13.7(9.9-17.5)$ & $2.6(0.3-4.9)$ \\
\hline \multicolumn{3}{|l|}{ Reasons for dissatisfaction } \\
\hline Lack of medicines & $64.8(55.8-73.8)$ & $26.5(20.2-32.8)$ \\
\hline Not all services available & $16.7(9.7-23.7)$ & $12.7(8.0-17.4)$ \\
\hline Clinic far away & $10.2(4.5-15.9)$ & $1.0(0.0-2.4)$ \\
\hline Quality of services not good & $8.3(3.1-13.5)$ & $4.3(1.4-7.2)$ \\
\hline Poor attitude of service providers & $8.3(3.1-13.5)$ & $1.1(0.0-2.6)$ \\
\hline Obtained family planning services if sought & $96.7(94.4-99.0)$ & $73.2(62.9-83.5)$ \\
\hline CURRENTLY USING CONTRACEPTIVES & $(\mathrm{N}=439)$ & $(\mathrm{N}=327)$ \\
\hline Obtained supplies from shop/pharmacy & $17.1(13.6-20.6)$ & $33.6(31.0-36.2)$ \\
\hline Low SES† & $13.2(8.5-17.9)$ & $20.9(15.1-26.7)$ \\
\hline Other & $20.2(15.1-25.3)$ & $50.7(42.4-59.0)$ \\
\hline Husband collected supplies from shop/pharmacy & $90.7(84.1-97.3)$ & $89.9(84.2-95.6)$ \\
\hline Low SES† & $92.3(82.1-100.0)$ & $94.9(88.0-100.0)$ \\
\hline Other & $89.8(81.3-98.3)$ & $87.1(79.2-95.0)$ \\
\hline
\end{tabular}

tWomen who had no schooling or whose husband was a day laborer.

Service providers and users in the surveillance areas seemed generally to have accepted the static clinic system. Overall, however, $82 \%$ of women in clinic wards (79\% in Abhoynagar and $85 \%$ in Mirsarai) reported that they would still value home visits; the main reasons given (data not shown) were that they received information from the fieldworkers $(65 \%)$ and that they did not have to leave their housework (21\%). On the other hand, $12 \%$ reported that regular home visits were not necessary because all services were available at the community clinic. When asked for suggestions for service provision, $42 \%$ of women mentioned (unprompted) that services should be provided in one place, and 22\% thought that medicines should be available. Opinion was divided when women in clinic wards were asked whether they preferred community clinics or home visits with satellite clinics. A small majority (54-55\%) of both women of low socioeconomic status and other women in the two upazilas favored the static clinic system.

\section{DISCUSSION}

The main trends in reported service use from 1998 to 2002 indicate that the proportion of women using community clinics (in wards where one was operational) increased, while the proportion relying on visits to satellite clinics and on home visits by fieldworkers declined. Although most community clinics did not become operational until 2001, use of the facilities increased rapidly and consistently over the next two years in both surveillance areas. By September 2003, about three-quarters of women with a community clinic in their ward had used it; the proportion was particularly high among young women, women with no schooling and those with low household expenditure. Many women had made several visits (data not shown); frequency of use is indicated by surveillance data showing that in every quarter of 2002 about 30\% of women in clinic wards in Abhoynagar and 20\% in Mirsarai had visited a community clinic.

The decline in visits to satellite clinics suggests that services provided at different locations on different days can be replaced without inconvenience by services at a static clinic, as few women reported problems resulting from the change. A small majority of women expressed a preference for the community clinic system. Many reported that they would still value home visits, but more for information than for contraceptive supplies. When household visits were phased out, community clinics quickly became the main source of contraceptives in Abhoynagar, and use of other government sources declined. In Mirsarai, the proportion of women using community clinics rose rapidly, along with the proportion relying on shops and pharmacies, although by the end of 2002 use of community clinics had overtaken use of other government sources, as occurred in Abhoynagar.

The proportion of women in both surveillance areas who obtained contraceptives from a fieldworker at home was already declining in 1998-2000, before a substantial decrease in reported home visits. The increasing use of shops and pharmacies during this time suggests that other factors were involved, possibly a preference for oral contraceptives not available from fieldworkers or other government sources. During the withdrawal of home visits in 2001-2002, the use of shops and pharmacies became much greater. Over the whole period 1998-2002, the proportion of women using these sources increased from 5\% to 15\% in both areas. These sources were more popular among women in the "other" socioeconomic group than among women of low socioeconomic status, which may reflect an ability to pay higher costs for preferred contraceptives. Although the shift to shops and pharmacies is consistent with the strategy of encouraging women to seek services outside the home, it raises important issues about quality of care. For example, women who relied on these sources probably had little direct access to information about side effects of the pill or to follow-up advice and care, because in most cases their husbands collected supplies.

Despite the phasing out of domiciliary services, overall contraceptive prevalence increased in Mirsarai. Although fieldworkers had been a major supplier of oral contracep- 
tives, the proportion of women using this method increased in clinic wards of both surveillance areas when routine visits were withdrawn. These increases occurred in the context of rising pill use in rural Bangladesh overall during the study period. ${ }^{16}$

Use of the injectable has also been increasing in rural Bangladesh overall, from 5\% in 1993-1994 to 10\% in 2004. ${ }^{17}$ The method was the second most popular method in both surveillance areas. Use was particularly high in Abhoynagar (15-25\%), where fieldworkers had received considerable training and provided the method through home visits. This had been done to a lesser extent in Mirsarai, and use of the injectable was much lower (10\%). The proportion of women using the injectable declined in 2000-2001 in clinic wards of Abhoynagar, most likely because of a shortage of supplies or the decline in domiciliary provision. However, prevalence returned to close to its previous level in 2002, when women were able to obtain the method at community clinics. In clinic wards of Mirsarai, where fieldworkers were not a major source of the injectable, use did not decline when domiciliary visits were phased out. Most women appear not to have been dependent on home delivery of the injectable. Women were clearly not dependent on home delivery of the pill, given the increasing use of this method in both areas while home visits were being phased out.

There is no evidence that trends for less popular methods of contraception were affected by the transition to community clinics. Reported use of traditional methods remained lower in clinic wards of both areas than in rural Bangladesh as a whole (2-4\% vs. 10\% in 1999-2000 and $11 \%$ in 2004), ${ }^{18}$ possibly because women in the surveillance areas had relatively good access to modern methods at government facilities. The proportion of women who reported relying on tubal sterilization declined from 1998 through 2002 in Abhoynagar and Mirsarai, both before and after community clinics became operational. Although this method was less common in the surveillance areas than in rural Bangladesh as a whole, the decline was consistent with the national downward trend reported in the DHS (from $8 \%$ in $1993-1994$ to $5 \%$ in 2004). The low proportion of women using IUDs in Abhoynagar and Mirsarai (2-3\%) corresponds to that among rural women nationally ( $1 \%$ in 1999-2000 and 2004). ${ }^{19}$

In a period of major change in the service delivery system and sources of contraceptives, only a minority of women in clinic wards of Abhoynagar and Mirsarai had changed their method in the two years before the 2003 survey. Very few of these women attributed the change to supply-side problems.

In 1998-2002, overall contraceptive prevalence remained at about $60 \%$ in the clinic wards of Abhoynagar and increased from $40 \%$ to $47 \%$ in Mirsarai. These levels and trends are consistent with those of the respective regions. Abhoynagar is in Khulna Division, where prevalence among married women remained at 64\% between 1999-2000 and 2004. Mirsarai is in Chittagong Division, where prevalence increased from $44 \%$ to $47 \%$ during that time. ${ }^{20}$
Mirsarai's relatively low prevalence may partly reflect the high proportion of couples separated by work migration: The surveillance data show that about one-quarter of women in the surveillance areas of Mirsarai had a husband who lived away from home for work. Not surprisingly, contraceptive prevalence was very low among these women, particularly among the approximately $17 \%$ of women whose husband was living abroad. ${ }^{21}$ The husbands who traveled for work tended to have slightly more schooling and occupational skills than other men. This may be reflected in contraceptive prevalence, which was consistently higher among women of low socioeconomic status than among others in Mirsarai but was roughly equal for the two groups in Abhoynagar.

The two surveillance areas are quite different and are not intended to be representative of their respective divisions. ICDDR,B's long-term presence conducting surveillance and its assistance with the community clinic guidelines and implementation process may have benefited implementation in Abhoynagar, where $71 \%$ of the 17 planned community clinics were operational in 2002, compared with 55\% of 1,599 clinics planned for the entire division. In Mirsarai, 42\% of the 19 planned community clinics were operational in 2002 , similar to the $41 \%$ of 2,709 operational clinics in the division. ${ }^{22}$ The proportion of planned clinics that became operational varied considerably across the other four divisions of Bangladesh, from 33\% in Barisal to 68\% in Rajshahi.

Unfortunately, there are no reliable data on use of community clinics in 1998-2000 for other areas of Bangladesh or for the entire country. However, if trends were less favorable outside the surveillance areas, they could reflect problems in implementation rather than the static clinic strategy. Levels of implementation varied within unions of the surveillance areas, which is likely to have been the case throughout Bangladesh. Nevertheless, the transition to static clinic service provision in some wards of the study areas illustrates what could be achieved even with partial implementation over only two years.

At the end of 2003, service providers reported that most community clinics in the surveillance areas were being used only for immunization. Although the new government had reinstated domiciliary services for the next sectoral program, ${ }^{23}$ most of the fieldworkers interviewed in the surveillance areas in September 2003 were in favor of community clinics because they enabled women to get all the services they needed in one place on any day of the week. Fieldworkers have some vested interest in the static clinic system, having benefited from a fixed location for their work and from reportedly increased status associated with employment at a community clinic. Women had experienced a similar gain in status when they were introduced as fieldworkers for domiciliary services. ${ }^{24}$

\section{CONCLUSIONS}

Our results indicate that women in two surveillance areas of rural Bangladesh have not become dependent on home delivery of family planning supplies. Rather, they rapidly 
switched to static clinics for family planning services when these facilities were functional and other government sources were withdrawn.

Increasing use of private sources of family planning supplies raises important issues related to quality of care, because in most cases the husband collects supplies. Women need direct access to family planning information, advice and follow-up services. Clearly, this is more of a problem when family planning services are not available at a static clinic, which was the case in many parts of Bangladesh in 1998-2002, and when the majority of women do not receive regular home visits from fieldworkers, as reported by DHS from 1994 to 2004.25

Our study shows that the transition to a static clinic system was largely achieved in several wards of two surveillance areas, albeit late in the sectoral program. About half (56\%) of planned community clinics became operational in the surveillance areas, a slightly higher proportion than in the country as a whole (49\%). It would be unwise to generalize from trends in service use and coverage in surveillance areas that are not representative of Bangladesh. However, we believe that the evidence from these areas indicates that static clinics can replace satellite clinics and provide a permanent focus of service provision in the community. Some home visits by female fieldworkers may still be required to promote use of services and to provide information to particular subgroups, including young married women and others not using contraceptives.

There is an urgent need in Bangladesh to develop evidence-based strategies for cost-effective delivery of family planning services, particularly to young women. Although the country has experienced a remarkable decline in the total fertility rate, from 6.3 in 1971-1975 to 3.0 in 2001-2003, ${ }^{26}$ rapid population growth will continue for many years even if fertility is reduced to replacement level or below. A considerable increase in contraceptive use is essential to further reduce fertility rates.

A prospective study is needed to monitor family planning service use and contraceptive prevalence in selected areas where domiciliary delivery is being properly implemented. Given the amount of resources already invested in community clinics, the static clinic system should be fully implemented in selected areas for comparative evaluation. Community clinics operated for a limited time (2001-2002), and many problems related to implementation already existed; thus they were not given a complete trial. ${ }^{27}$ Further evaluation could be conducted in collaboration with NGOs, many of which have been effective in achieving high coverage of reproductive and child health services by implementing government strategies. ${ }^{28}$ Comparative evaluation of the cost-effectiveness of these service delivery systems, based on user-reported data, would inform the development of family planning services in Bangladesh.

\section{REFERENCES}

1. Cleland J et al., The Determinants of Reproductive Change in Bangladesh: Success in a Challenging Environment, Washington, DC: International Bank for Reconstruction and Development and World Bank, 1994; Schuler SR et al., The advent of family planning as a social norm in
Bangladesh: women's experiences, Reproductive Health Matters, 1996, No. 7, pp. 66-78; and Phillips JF et al., Evidence-Based Development of Health and Family Planning Programs in Bangladesh and Ghana, Policy Research Division Working Papers, New York: Population Council, 2003, No. 175.

2. Phillips JF and Hossain MB, The impact of household delivery of family planning services on women's status in Bangladesh, International Family Planning Perspectives, 2003, 29(3):138-145; and Routh S et al., Consequences of the shift from domiciliary distribution to site-based family planning services in Bangladesh, International Family Planning Perspectives, 2001, 27(2):82-89.

3. Routh S et al., 2001, op. cit. (see reference 2).

4. Rahman MB et al., Productivity and Cost of Family Planning Service Delivery in Bangladesh: The NGO Program (Main Report), Dhaka, Bangladesh: Population Development and Evaluation Unit, Ministry of Planning, Government of Bangladesh, Associates for Community and Population Research and Family Health International, 1996; and Routh S et al., Developing alternative service delivery strategies for delivery of MCH-FP services in the urban areas: findings from an experiment, Working Paper, Dhaka, Bangladesh: International Centre for Diarrhoeal Disease Research, Bangladesh (ICDDR,B), 1997, No. 106.

5. Mitra SN et al., Bangladesh Demographic and Health Survey 1993-1994 Calverton, MD, USA: National Institute of Population Research and Training (NIPORT), Mitra and Associates and Macro International, 1994; and Mitra SN et al., Bangladesh Demographic and Health Survey 19961997, Calverton, MD, USA: NIPORT, Mitra and Associates and Macro International, 1997.

6. Ministry of Health and Family Welfare (MOHFW), Health and Population Sector Programme 1998-2003; Programme Implementation Plan, Part I, Dhaka, Bangladesh: Government of Bangladesh, 1997.

7. Schuler SR et al., The persistence of a service delivery "culture": findings from a qualitative study in Bangladesh, International Family Planning Perspectives, 2001, 27(4):194-200.

8. Hossain MB and Phillips J, The impact of outreach on the continuity of contraceptive use in rural Bangladesh, Studies in Family Planning, 1996, 27(2):98-106.

9. Schuler SR et al., 2001, op. cit. (see reference 7); and Bates LM et al., From home to clinic and family planning to health: client and community responses to health sector reforms in Bangladesh, International Family Planning Perspectives, 2003, 29(2):88-94.

10. Streatfield PK et al., Health and Population Sector Programme 1998-2003. Status of Performance Indicators 2002: A Report for the Health Programme Support Office for the Annual Programme Review, 2002, Dhaka, Bangladesh: ICDDR,B, Centre for Health and Population Research, 2003.

11. MOHFW, Conceptual Framework for Health, Nutrition and Population Sector Programme, July 2003-June 2006, Dhaka, Bangladesh: MOHFW, 2003.

12. Sarker S et al., Operations Research on ESP Delivery and Community Clinics in Bangladesh: Preliminary Assessment of Performance of Two Selected Community Clinics, Special Publication, Dhaka, Bangladesh: Family Health Research Project, Health Systems and Infectious Diseases Division, ICDDR,B, 2002, No. 114

13. MOHFW, Operational Manual for Community Clinics; Guidelines on Operation, Management and Functioning of Community Clinics, October 2000, Dhaka, Bangladesh: Government of Bangladesh, 2000.

14. NIPORT, Mitra and Associates and Macro International, Bangladesh Demographic and Health Survey 1999-2000, Calverton, MD, USA: NIPORT, Mitra and Associates and Macro International, 2001; and NIPORT, Mitra and Associates and ORC Macro, Bangladesh Demographic and Health Survey 2004, Calverton, MD, USA: NIPORT, Mitra and Associates and ORC Macro, 2005; and Canadian Institute for Energy Training, Health and Population Sector Programme 1998-2003, Bangladesh: Service Delivery Survey, Second Cycle, 2000, Dhaka, Bangladesh: MOHFW, 2001

15. NIPORT, Mitra and Associates and Macro International, 2001, op cit. (see reference 14).

16. Ibid.; and NIPORT, Mitra and Associates and ORC Macro, 2005, op. cit. (see reference 14).

17. Mitra SN et al., 1994, op. cit. (see reference 5); NIPORT, Mitra and 
Associates and Macro International, 2001, op. cit. (see reference 14); and NIPORT, Mitra and Associates and ORC Macro, 2005, op. cit. (see reference 14 ).

18. NIPORT, Mitra and Associates and Macro International, 2001, op. cit. (see reference 14); and NIPORT, Mitra and Associates and ORC Macro, 2005, op. cit. (see reference 14).

19. Ibid.

20. Ibid

21. Reza M and Larson CP, Families of migrant workers: patterns of health service use and coverage, Abstracts Book: 10th Asian Conference on Diarrhoeal Diseases and Nutrition, Dhaka, Bangladesh: ICDDR,B Centre for Health and Population Research, 2003.

22. Streatfield PK et al., 2003, op. cit. (see reference 10).

23. MOHFW, 2003, op. cit. (see reference 11).

24. Phillips JF and Hossain MB, 2003, op. cit. (see reference 2).

25. Mitra SN et al., 1994, op. cit. (see reference 5); Mitra SN et al., 1997, op. cit. (see reference 5); NIPORT, Mitra and Associates and Macro International, 2001, op. cit. (see reference 14); and NIPORT, Mitra and Associates and ORC Macro, 2005, op. cit. (see reference 14).

26. NIPORT, Mitra and Associates and ORC Macro, 2005, op. cit. (see reference 14 ).

27. Bates LM et al., 2003, op. cit. (see reference 9).

28. Mercer A et al., Effectiveness of an NGO primary health care programme in rural Bangladesh: evidence from the management information system, Health Policy and Planning, 2004, 19(4):187-198.

\section{RESUMEN}

Contexto: En las zonas rurales de Bangladesh, los servicios de planificación familiar-anteriormente suministrados mediante visitas a los hogares y en clínicas satelitales-fueron transferidos a las clínicas comunitarias fijas, bajo el programa sectorial del gobierno para 1998-2003, aunque el próximo programa sectorial revirtió el cambio sin realizar una evaluación previa. Es importante evaluar los cambios con respecto a la utilización y la cobertura de servicios para disponer de la información que permita una toma de decisiones adecuada sobre cambios adicionales del sistema de distribución de servicios.

Métodos: Se recopilaron datos longitudinales sobre el uso de los servicios de planificación familiar y métodos anticonceptivos trimestralmente desde 1998 a 2002, de mujeres casadas de aproximadamente 11.000 hogares, en dos zonas rurales de observación-Abhoynagar y Mirsarai. Se realizaron encuestas transversales a mujeres y proveedores de servicios, en 2003, para recabar información sobre la transición de las clínicas satelitales y la respuesta de las mujeres ante estos cambios. Se trazaron gráficos cronológicos trimestrales de indicadores seleccionados para las áreas a las que las clínicas comunitarias prestaban servicios. Resultados: En un momento de cambios considerables en el suministro y fuentes de servicios de anticonceptivos, la prevalencia del uso de anticonceptivos permaneció constante en Abhoynagar y aumentó en Mirsarai. Las clínicas comunitarias se convirtieron rápidamente en la fuente de los métodos para un tercio de las usuarias de Abhoynagar y para un quinto de las de Mirsarai. En los barrios donde las clínicas comunitarias volvieron a funcionar (en su mayoría en 2001-2002), tres cuartas partes de las mujeres habian usado los servicios de una de ellas alguna vez.

Conclusiones: A pesar de las restricciones culturales con respecto a la movilidad, las mujeres no parecen haberse vuelto dependientes de un sistema de distribución domiciliaria de anticonceptivos.

\section{RÉSUMÉ}

Contexte: Au Bangladesh rural, les services de planning familial-auparavant assurés dans le cadre des visites de ménage et cliniques satellites-ont été transférés aux cliniques communautaires statiques sous le programme sectoriel de l'État de 1998-2003. Le programme sectoriel suivant renverse toutefois ce changement sans évaluation formelle. Il importe d'évaluer les changements d'utilisation et de couverture au soutien du développement à venir du système de prestation des services.

Méthodes: Des données longitudinales de recours aux services du planning familial et aux méthodes contraceptives ont été recueillies tous les trois mois, de 1998 à 2002, auprès des femmes mariées d'environ 11.000 ménages de deux zones de surveillance rurales-Abhoynagar et Mirsarai. Des enquêtes transversales ont été menées en 2003 auprès des femmes et des prestataires afin de documenter en détail la transition aux cliniques statiques et la réponse des femmes au changement. Des chronogrammes trimestriels d'indicateurs sélectionnés ont été tracés pour les zones servies par les cliniques communautaires.

Résultats: En une période de changement considérable des prestations et sources d'approvisionnement, la prévalence contraceptive est demeurée constante à Abhoynagar et a augmenté à Mirsarai. Les cliniques communautaires sont vite devenues la source d'approvisionnement d'un tiers des utilisatrices à Abhoynagar et d'un cinquième à Mirsarai. Dans les quartiers où les cliniques communautaires étaient devenues opérationnelles (en 2001-2002 surtout), trois quarts des femmes s'y étaient adressées.

Conclusions: Malgré les contraintes culturelles de mobilité, les femmes ne semblent pas être devenues dépendantes de la livraison à domicile de contraceptifs.

\section{Acknowledgments}

This project was supported by a research grant from the UK Department for International Development (DFID), Bangladesh. The views expressed are the authors' and do not necessarily reflect those of DFID.

Author contact: amercer@icddrb.org; nashraf@icddrb.org 